\title{
AN ANALYSIS OF SAILORS' CONFIDENCE LEVEL IN PERSONAL LIFE-SAVING APPLIANCES AND BUOYANCY AIDS
}

In the article, an attempt was made to determine the level of sailors' confidence in personal life-saving appliances and buoyancy aids when practising sports and recreational sailing at sea. The article presents results of the research conducted on a sample composed of 40 seagoing sailors aged 18+, who participated in the IX International Sailing Regatta Eljacht Cup 2018. The method used to carry out the research was the method of a diagnostic survey. The applied research technique consisted of a questionnaire. As the conducted research has shown, in Poland, this sport is more popular among men than women. The vast majority of sailors have received higher education. The majority of people who enjoy sailing live in cities ranging from 100,000 to 200,000 inhabitants.

Sailing as a water sports discipline is becoming an activity which is relatively easy to be taken up by women as well as men of all ages. In Poland, the model of sailing tourism itself has undergone significant transformations over the last two decades. The reason for these changes is an increase in the society's affluence. Even at the beginning of the 20th century, sailing was still an activity that was quite an elite sport and was practised as part of sailing clubs. Nowadays on the commercial market, there are companies that specialize in yacht charter and are ready to make their vessels available on any water and during any season. The number of private ship owners is also on the rise. Yacht crews are obliged to follow many procedures once they board the vessel. Safety on the yacht is the most important factor. Without going into details, it depends on the way a vessel has been constructed and how it is equipped, the qualifications and training of its crew, as well as the observance of good seamanship. Good seamanship - "good seamanship is: the whole of written and, especially, unwritten general recommendations for conduct, which may be considered the embodiment of a sailor's common" (Monsarrat, 1988).

Keywords: level of sailors' confidence in personal life-saving appliances, sailing tourism, water sports discipline, good seamanship.

${ }^{1}$ Hanna Sommer, PhD, Department of Humanities and Social Sciences, Faculty of Management, Rzeszów University of Technology, Al. Powstańców Warszawy 8, 35-959 Rzeszów; e-mail: hansom@prz.edu.pl. ORCID: 0000-0001-7208-7641.

${ }^{2}$ Grzegorz Zakrzewski, PhD, Eng., University of Security in Poznań, ul. Marynarki Polskiej 15, 80-557 Gdańsk; e-mail: grzegorz.zakrzewski@wsb.net.pl. ORCID: 0000-0002-0945-5322. 


\section{INTRODUCTION}

The Earth is the only planet known in the Solar System, on which life has evolved. Air, water, earth and life - including humankind - together create a constantly changing world. They say that the Earth is the planet of life. In this case, the word "earth" has the colloquial meaning of "dry land". Earth's surface totals: 510.22 million $\mathrm{km}^{2}$, including the area of lands amounting to 149.16 million $\mathrm{km}^{2}(29 \%)$ and the area of oceans making up 361.06 million $\mathrm{km}^{2}$ (71\%) (Dimensions of the Earth, http://www.naukowiec.org/tablice/geografia/wymiary-ziemi_2734.html). The world's oceans are the least examined environment on our planet. However, this does not pose a problem for people who engage in sailing. We wrote about collective life-saving appliances - a pneumatic life raft, in the article: Attitudes of contemporary academic youth in an emergency situation (with the use of rescue equipment) (H. Sommer, H. Sommer, Zakrzewski, 2018). This article is a continuation related to the issues of sailors' safety. We will discuss personal life-saving appliances and buoyancy aids. The necessity of providing vessels with life-saving appliances is imposed by the "Life Saving Appliances Code which is a code "|belonging" to the SOLAS Convention (Chapter III, art. 34) (https://puc.overheid.nl/nsi/doc/PUC_2393_14/5/). The provisions included in it concern the characteristics and capacity of the following elements:

- Individual life-saving appliances - lifebuoys, life-belts, immersion suits, anti-exposure suits and thermal protective aids.

The Code regulates the following parameters of a lifebuoy:

- The inner diameter of no less than $40 \mathrm{~cm}$ and the weight of over $2.5 \mathrm{~kg}$.

- They should be constructed of inherently buoyant material.

- A lifebuoy should not sustain burning or continue melting (after being totally enveloped in a fire for a period of 2 seconds).

- It should support $14.5 \mathrm{~kg}$ for 24 hours.

- It should withstand a drop into the water form $30 \mathrm{~m}$ (or the height at which it is stowed in the lightest sea-going condition, depending on whichever is the greater).

- Equipment (a lifebuoy with a light, a grab-line or a light and smoke signal).

- Grab-line with a length of 4 times the diameter of the lifebuoy.

- Lights such that they cannot be extinguished by water, light of white colour, intensity of $2 \mathrm{~cd}$, light either fixed or flashing (50-70 flashes/min), battery capacity $-2 \mathrm{~h}$.

- Lifebuoy smoke signals should emit smoke for at least 15 min., they should not stop emitting smoke while totally submerged for $10 \mathrm{~s}$.

Life-belts:

- Classic belts - in which buoyancy is achieved thanks to the use of an inherently buoyant material.

- Inflatable (pneumatic) belts - in which buoyancy is provided by buoyancy chambers filled with carbon dioxide.

- Belts are to be put on in 1 minute, there is only one possibility of putting them on.

- They make it possible to jump from a height of 4.5 meters.

- The belt rotates the body so that it is positioned on the back in 5 seconds.

- After 24 hours, the buoyancy may be reduced by no more than 5\%. 
- Life-belt lights with an intensity of over $0.75 \mathrm{~cd}$ and with a battery lasting 8 hours, as well as using either a fixed or flashing light (50-70 flashes) are to be equipped with a switch.

Immersion suit:

- The task of the suit is to protect the survivor, mainly against excessive temperature loss.

- Immersion suits that do not meet the requirements applicable to life-belts must be used together with a belt.

- They are additionally equipped with a light and a whistle.

- It is possible to put an immersion suit on by oneself in 2 minutes.

- It does not sustain burning or continue melting after being engulfed in flames for 2 seconds.

- It allows to move freely (go down a ladder, jump into the water, swim a short distance, enter a rescue unit).

- Suits characterized by insulating properties do not allow the body temperature to drop more than $2^{\circ} \mathrm{C}$ over a period of being immersed for 6 hours in water at a temp. of $0-2^{\circ} \mathrm{C}$.

- Suits not characterized by insulating properties are to be used together with warm clothing, they shall not allow the body temperature to decrease by more than $2^{\circ} \mathrm{C}$ over a 1 -hour period of being immersed in water at a temp. of $5^{\circ} \mathrm{C}$ ".

"Thermal protective aids

- Made of waterproof material that reduces heat loss.

- Along with a life jacket, it covers the whole body except for the face.

- It can be taken off in water in no more than 2 minutes if it makes it difficult to stay above water.

- Used primarily as a buoyant aid may be used at a temperature ranging from $-30^{\circ} \mathrm{C}$ to $+20^{\circ} \mathrm{C}$ " (LSA Code-characteristics of life-saving appliances, http://ratownictwo. am.szczecin.pl/index.php/dla-studentow/ratownictwo-morskie/31-kodeks-lsa).

Due to the intention of the article, which is the assessment of the confidence in selected personal life-saving appliances and in selected appliances supporting the safety of a sailor, a number of detailed regulations have been omitted. However, it should not be forgotten that the equipment on a yacht is influenced, among others, by:

- The provisions of the registration office of the country where a given vessel is registered (Polish Register of Shipping) (See more https://www.prs.pl/_files/parent519/rejestr_jac_2017.pdf [Access: 2019.01.29]),

- The insurer's requirements applicable to a given cruise.

Old and reliable buoyancy aids are also used on yachts, in addition to modern solutions from the electronics industry, depending on the wealth of the ship owner.

- Rescue waists - thin and comfortable, collarless, increase buoyancy in the event of falling overboard.

- Preventive waists - e.g. the so-called "lifeline" (Life-saving and security appliances, https://www.zeglarstwo.waw.pl/srodki.htm) is attached with a snap hook to special fixtures on the deck - mainly in sea sailing, it should be used in any weather conditions, and especially in difficult ones. In the event of falling overboard, it eliminates the risk of drifting away from the yacht. Sailors often use the so-called. 
- Safety harness, which has 2 wires ending in snap hooks, allowing the harness to be attached to the "lifeline".

- Technical novelties not governed by international/national regulations, such as, for example, an electronic siren alerting that someone has fallen overboard.

Essential legal acts/Legal provisions applicable to yacht sailing.

Yacht sailing requires the yacht's crew to have special qualifications. Skipper's licences are documents specified in the Regulation of the Minister of Sports and Recreation of 9 April 2013 on practising water tourism. Qualifications granted by the licences are summarized in Table 1.

Table 1. Skipper's licences - requirements - qualifications

\begin{tabular}{|c|c|c|}
\hline Skipper's licence & Requirements & Qualifications \\
\hline Yacht Sailor & $\begin{array}{l}\text { - being at least } 14 \text { years of age, } \\
\text { - passing an exam testing the required } \\
\text { knowledge and skills. }\end{array}$ & $\begin{array}{l}\text { - navigating sailing yachts not } \\
\text { equipped or equipped with an } \\
\text { auxiliary mechanical drive } \\
\text { through inland waterways } \\
\text { without restrictions, } \\
\text { - navigating sailing yachts with a } \\
\text { length of up to } 12 \mathrm{~m} \text { at sea } \\
\text { through internal sea waters, } \\
\text { and, for the remaining sea wa- } \\
\text { ters located } 2 \text { miles away from } \\
\text { the shore, at daytime. }\end{array}$ \\
\hline $\begin{array}{l}\text { Marine Yacht } \\
\text { Helmsman }\end{array}$ & $\begin{array}{l}\text { - being at least } 18 \text { years of age, } \\
\text { - completing at least two sea voyages } \\
\text { amounting to at least } 200 \text { hours of } \\
\text { sailing since obtaining the licence of } \\
\text { a Yacht Sailor, } \\
\text { - passing an exam testing the required } \\
\text { knowledge and skills. }\end{array}$ & $\begin{array}{l}\text { - navigating sailing yachts not } \\
\text { equipped or equipped with an } \\
\text { auxiliary mechanical drive } \\
\text { through inland waterways with- } \\
\text { out restrictions, } \\
\text { - navigating sailing yachts not } \\
\text { equipped or equipped with an } \\
\text { auxiliary mechanical drive with } \\
\text { a hull length of up to } 18 \mathrm{~m} \\
\text { through sea waters } \\
\end{array}$ \\
\hline Yacht Captain & $\begin{array}{l}\text { - possessing a Maritime Yacht Helms- } \\
\text { man licence, } \\
\text { - completing at least six seagoing voy- } \\
\text { ages amounting to at least } 1200 \text { hours } \\
\text { of sailing since obtaining the licence } \\
\text { of a Maritime Yacht Helmsman, in- } \\
\text { cluding at least } 400 \text { hours of inde- } \\
\text { pendently navigating a vessel with } \\
\text { a total length of more than } 7.5 \mathrm{~m} \text { and } \\
\text { completing at least one voyage span- } \\
\text { ning over } 100 \text { hours of sailing on } \\
\text { a vessel with a total length of more } \\
\text { than } 20 \mathrm{~m} \text {. }\end{array}$ & $\begin{array}{l}\text { - navigating sailing yachts not } \\
\text { equipped or equipped with an } \\
\text { auxiliary mechanical drive } \\
\text { through inland waterways with- } \\
\text { out restrictions, } \\
\text { - navigating sailing yachts not } \\
\text { equipped or equipped with an } \\
\text { auxiliary mechanical drive } \\
\text { through inland waters without } \\
\text { restrictions, }\end{array}$ \\
\hline
\end{tabular}

Source: Compiled based on (Regulation of the Minister of Sport and Recreation of 9 April 2013 on practising water tourism. Journal of Laws from 2013, item 460, http://prawo. sejm.gov.pl/isap.nsf/download.xsp/WDU20130000460/O/D20130460.pdf, p. 2-3). 
Due to international character of sailing it is crucial that legal regulations are understood the same way under different latitudes. None of the sailing family members contests documents giving a right to sail. A separate issue is following the rules of maritime practice. It is incomparable among crews if we consider under which flag they are registered. It can be easily noticed during regattas as well on sea as in ports. It is also a question of broadly understood maritime culture. The maritime behaviors represented by flags of convenience are unaccepted not only by naval society but also many countries decide not to let ships under flags of convenience enter the ports. It is not a secret that a strong currency is pushing out the weak one. The same situation can be observed in sailing traditions and habits. Great place to exchange views are: literature (More on https://www.onboardonline.com/industryarticle-index/features/perspectives-on-the-safety-culture-in-yachting/), sailing forums (More on https://forum.zegluj.net/, https://www.sailforum.pl/), formal trainings and informal meetings with sailing personalities. Experts of this article were: Witold Wajdeczko (email: sealight@ sealight.pl ${ }^{\text {- }}$ - technical advice, Wojciech Pałkowski ${ }^{3}$ - yachting advice. Our experts concluded long brainstorm in captains mess with following words: we hope we live to see the day when using assurance equipment will be as common as fastening seatbelts in a car.

\section{METHODOLOGICAL ASPECTS OF THE RESEARCH}

The main purpose of the conducted research was to check whether and to what extent yacht crews have confidence in personal life-saving appliances and buoyancy aids.

The method used to carry out the research was the method of a diagnostic survey, which allows to gather personal opinions on the analysed issue. The applied research technique consisted of a questionnaire form completed by the sailors themselves.

The research was conducted on a sample composed of 40 sea-going sailors aged 18+, who participated in the IX International Sailing Regatta Eljacht Cup 2018 on August 17-19 ( ( $^{\text {th }}$ International Regatta Eljacht Cup 2018, http://www.eljachtcup.pl/) this year, during a stopover at the GOS regatta port in Górki Zachodnie (See more: https://www. sportgdansk.pl/obiekty/przystan-jachtowa-gorki-zachodnie/).

The weather forecast is of utmost importance to a sailor. It is the weather forecast that allows one to plan a cruise, as well as to carry it out in safe conditions. On the day of the research, the meteorological conditions were as follows: A south-east wind gradually turning into a north-east one which, in the afternoon, changed into a north-west wind turning into a west one with a value of 2 to 3 degrees, with gusts reaching 4 degrees and, in the evening, a wind fluctuating between 2 and 4 degrees on the Beaufort scale. Air temperature $22^{\circ} \mathrm{C}$, water temperature $19^{\circ} \mathrm{C}$ (See more about the current weather forecast for sailors at: http://baltyk.pogodynka.pl/index.php?page=2\&subpage=6\&data=26).

\footnotetext{
${ }^{3}$ Wojciech Pałkowski, born 1959. Graduate of Polish Naval Academy. 1983-1996 officer on various ships of Polish Navy. 1996-2007 Deputy Chief of Sailing Training Center of Navy. Since 2007 senior officer on rescue ships in Maritime Search and Rescue Service. Practicing sea sailing since 1978. Owner of Certificate of Competency of Yachtmaster, Certificate of Competency of Ocean Going Motorboat Master. Experienced with several tens of cruises on Baltic Sea, North Sea, Atlantic Ocean and Mediterranean Sea. In 1999 awarded in Cruise of the Year Competition. Practicing inland sailing and canoeing.
} 


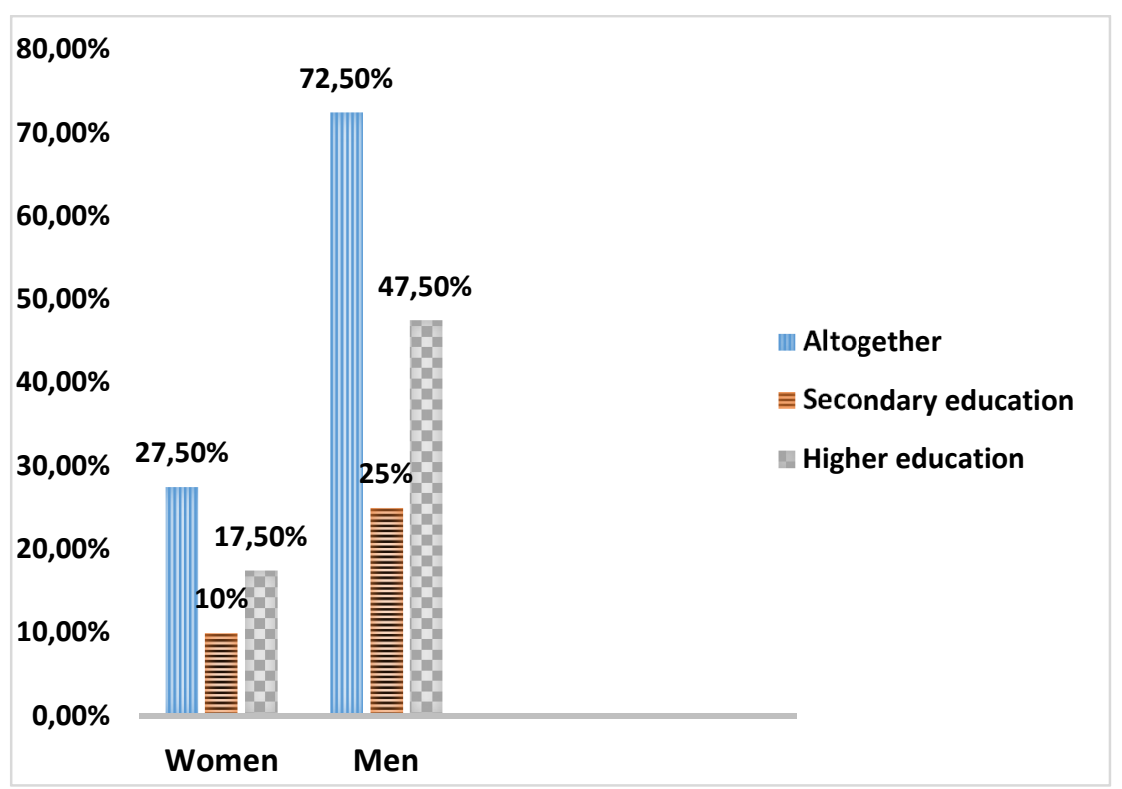

Chart 1. Sex and education on the respondents

Source: authors' own research

Among all the sailors participating in the study, 27.5\% of them were women and $72.5 \%$ were men. Such a sample selection was dictated by the sex of the participants of the regatta. On this basis alone, it may already be stated that this sport is more popular among men than women.

As far as the education of the respondents is concerned, clear disproportions are visible between secondary and higher education, both among women and men. $10 \%$ of the women and $25 \%$ of the men surveyed have completed secondary education, while $17.5 \%$ of women and $47.5 \%$ of men have higher education. Such a level of education of the respondents participating in the regatta shows that the vast majority of people involved in the sport have higher education.

As shown in Chart 2, most people who enjoy sailing live in cities ranging from 100,000 to 200,000 inhabitants $(55 \%)$. Among the respondents, $17.5 \%$ of them live in towns ranging from 50000 to 100000 inhabitants; the same percentage of respondents live in cities with over 200000 inhabitants. A small percentage of the respondents live in towns of up to 50 000 inhabitants and no participant of the regatta lives in the countryside. It might be said that inhabitants of medium-size towns engage in sailing and that it is not a source of entertainment for those who live in the countryside and in small towns. The largest number of sailors taking part in the research comes from the following provinces: Pomorskie, Mazowieckie, Śląskie, Kujawsko-Pomorskie and Warmińsko-Mazurskie.

As shown in Chart 3, the majority of enthusiasts of sailing, 37.5\%, are between 41 and 50 years of age, $27.5 \%$ of them are above 50 years old. Meanwhile, $20 \%$ of the respondents are between 31 and 40 years old, and $15 \%$ are between 20 and 30 years old. This demonstrates that the sport is mostly for people who already have a stable professional and private life. They have a stable financial situation, they do not have to look after their children who 
have already grown into adults, and they can devote themselves to their passion, which requires considerable financial resources, time and commitment.

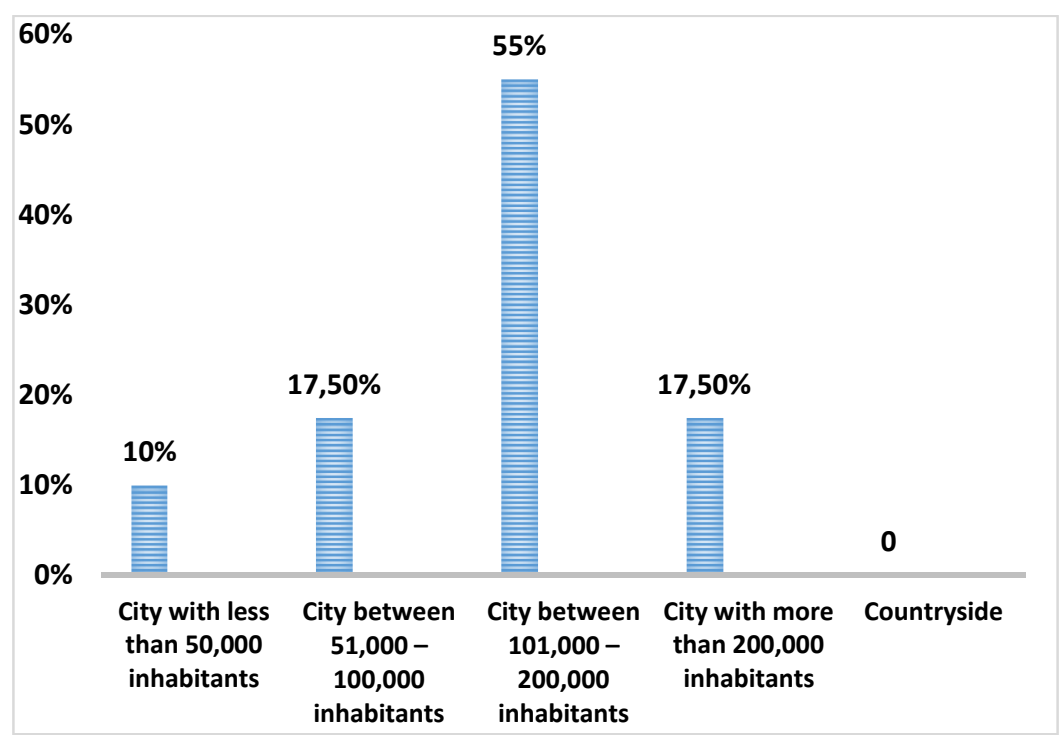

Chart 2. Place of residence of the respondents

Source: authors' own research

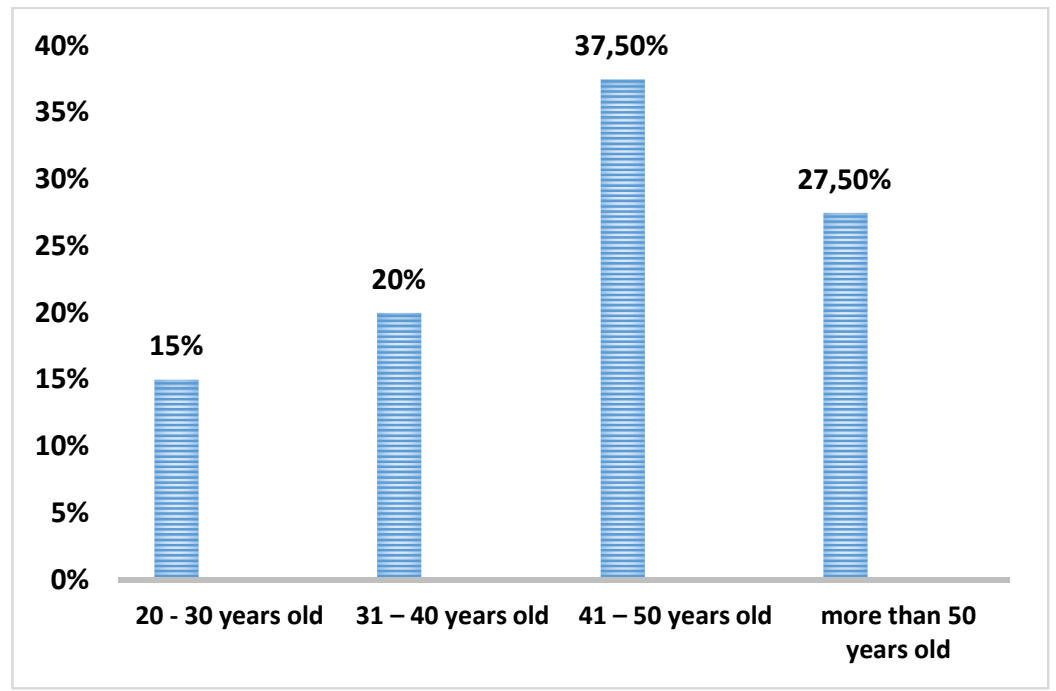

Chart 3. Age of the respondents

Source: authors' own research. 
According to the results of the research, people who participated in the regatta, have been involved in this sport for various amounts of time, from a year to over 40 years. The most numerous group of respondents are people who declare they have been involved in sailing for between more than 11 and 20 years (30\%). In turn, the least numerous group are those respondents, who have started their adventure with sailing over 40 years ago (5\%). A very large share of the respondents is experienced sailors who have been passionate about this pastime for years.

As many as $42.5 \%$ of the respondents have not taken part in offshore regattas until now. More than $32 \%$ of the participants have already taken part in regattas from 1 to 5 times, while $12 \%$ of the respondents have participated in regattas from 5 to 10 times and over $12 \%$ have been involved in such competitions more than 10 times.

Most of the respondents hold the licence of a maritime yacht helmsman (40\%), a sailor (30\%) or a captain $(17.5 \%)$. Additionally, some of the respondents boasted about holding the licence of a motorboat helmsman. Meanwhile, $12.5 \%$ of the respondents taking part in the regattas did not have a sailing licence.

During the described regattas, $35 \%$ of the respondents performed the role of a captain, $22.5 \%$ that of an officer, and $42.5 \%$ were members of the crews surveyed.

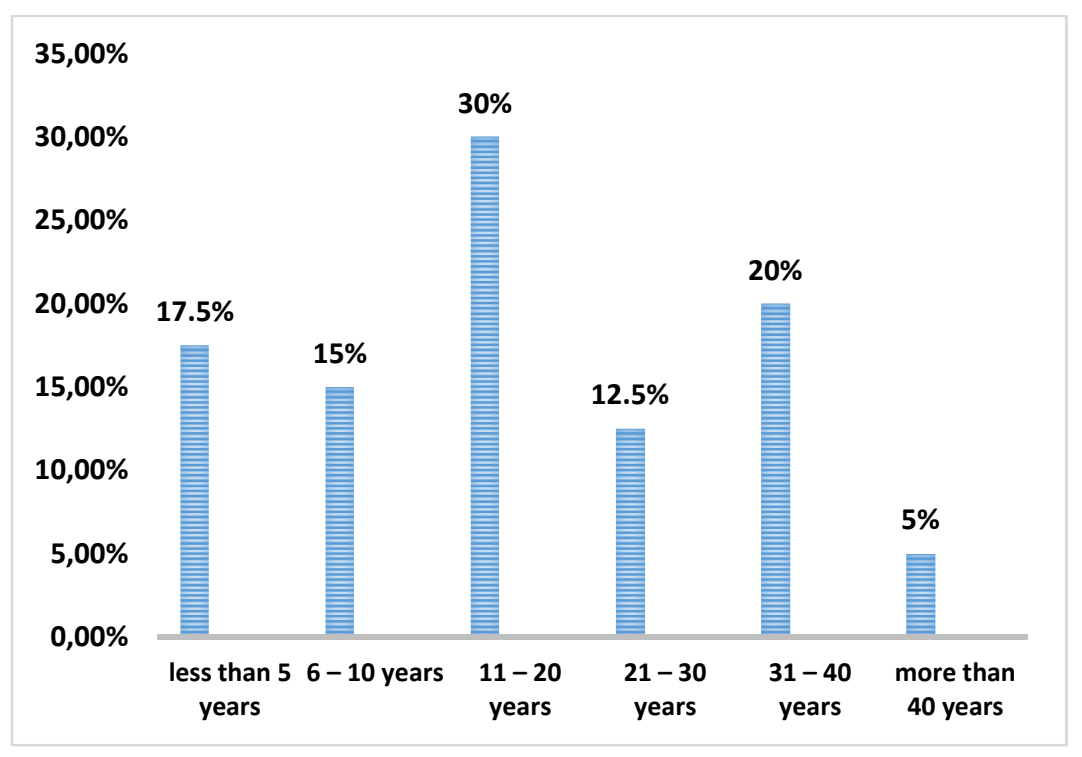

Chart 4. Years of being involved is sailing

Source: authors' own research.

Inland sailing around Poland (Masuria, Pomerania) constitutes the vast majority of cruises among the respondents. The Adriatic Sea and the Mediterranean Sea dominate among the foreign destinations chosen by the sailors surveyed. Few people have experiences related to the Atlantic, the North Sea or the Pacific. Some individuals could boast about having sailed around the whole world. 
Chart 5 illustrates sailing skills in the assessment of the respondents. Each participant could rate them on a scale from 1 to 5 , where 1 signifies bad skills and 5 very good ones. Most respondents rated their skills as good (32.5\%), slightly fewer, 30\%, as sufficient. 15\% of the respondents each described them as basic and as very good, which is the maximum rating on the scale used. Only $7.5 \%$ rated their sailing skills as bad. The surveyed sailors spoke quite positively about their skills. These results show that the sailors are well-prepared for practising this sport. The majority of the respondents sail on yachts which have a total sail area of up to $100 \mathrm{~m}^{2}(57.5 \%)$, and $42.5 \%$ of them on yachts with a sail area of above $100 \mathrm{~m}^{2}$.

When asked about people associated with sailing, the respondents often mention Krzysztof Baranowski, Roman Paszke, Mateusz Kusznierewicz, Leonid Teliga or Aleksander Doba. The vast majority of the respondents (65\%) had the opportunity to sail with an outstanding sailor, whom they treated as a guru and a role model in the field of sailing.

Equipment is a crucial subject for both professional and beginner sailors. The vast majority of the sailors surveyed consider a set of life-saving appliances such as life-jackets, lifebuoys, life-belts and safety harnesses as indispensable on the deck of a yacht used for bay/coastal sailing. Meanwhile, in the case of maritime navigation, in addition to the previously mentioned life-jackets, lifebuoys, life-belts or safety harnesses, there also appear a life raft, EPIRB (Radiopława EPIRB - basic information, https://www.egmdss. com/gmdss-courses/mod/resource/view.php?id=485), flares and immersions suits.

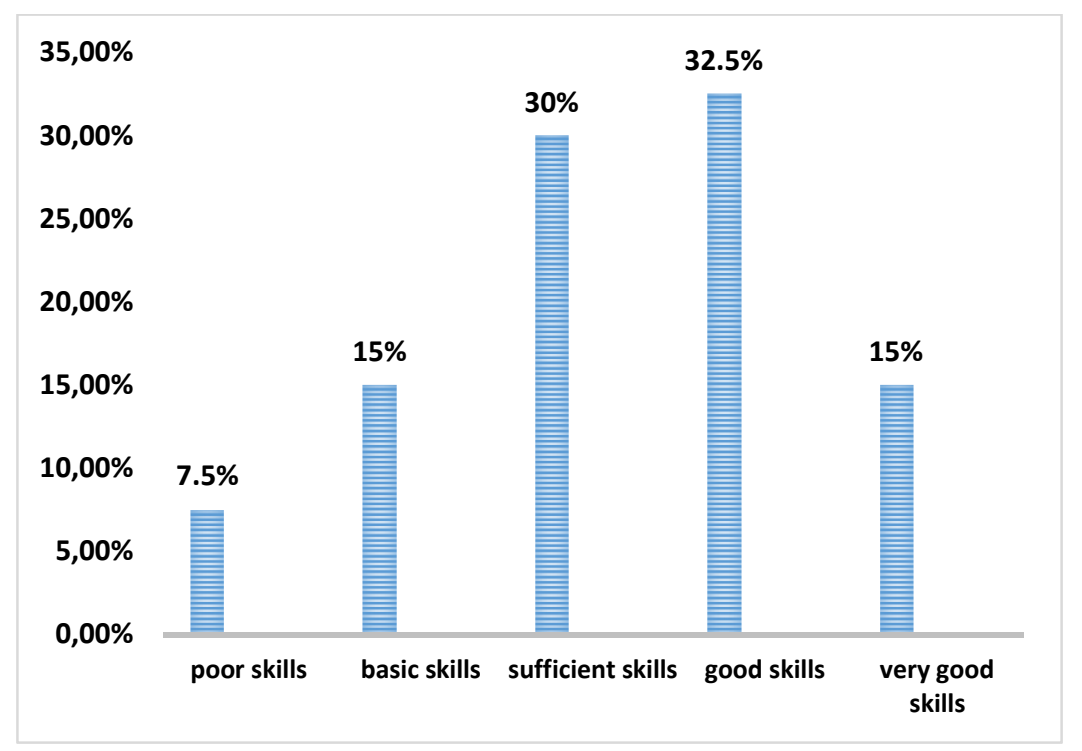

Chart 5. Subjective assessment of one`s own skills as a sailor

Source: authors' own research.

Most respondents are able to give examples of marine accidents involving Polish sailors. Most often, they mention S/Y Bieszczady, S/Y Rzeszowiak, S/Y Sunrise with captain Jacek Zieliński on-board, the tragedy at the North Sea or at the Indian Ocean in 2017. 
Over $32 \%$ of the respondents found themselves in a life-threatening situation at sea while sailing. While being in a difficult situation, they made use of the life-saving appliances they possessed, such as life-jackets, life-belts or immersion suits. Some of them used the assistance of SAR (MARITIME SEARCH AND RESCUE SERVICE, http://www.sar.gov.pl/pl/).

The sailors surveyed are aware of the necessity to use life-saving appliances while sailing. In a life- and health-threatening situation, sailing in severe weather when the wind force reaches $5^{0} \mathrm{~B}$ and the condition of the sea is dangerous and exceeds $5^{0} \mathrm{~B}$, the sailors use lifejackets, lifebuoys, safety harnesses, life-belts or immersion suits.

The participants of the above-mentioned regattas had the opportunity to see rescue equipment demonstrations. For $42.5 \%$ of the respondents, the display of rescue equipment was a novelty. They saw it for the first time. The same percentage of the respondents participated in such shows up to 10 times, and $15 \%$ of the respondents saw them more than 10 times.

The people surveyed could also evaluate this type of training (a lecture accompanied by a demonstration). The results are shown in Chart 6.

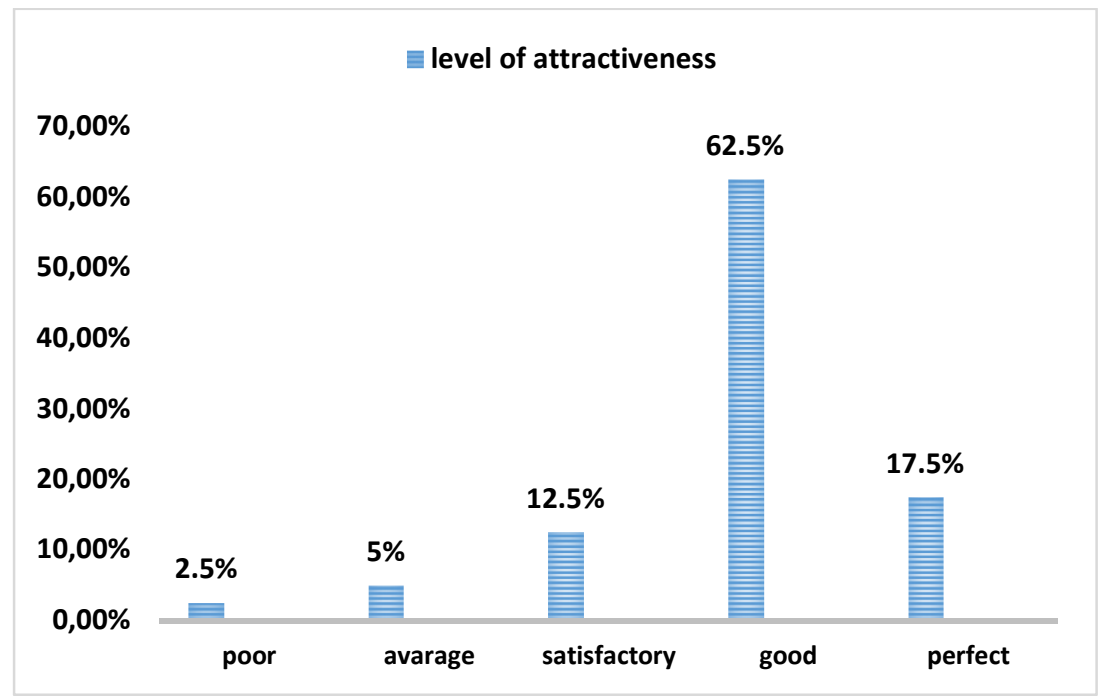

Chart 6. Assessment of the attractiveness (lecture with demonstration) of the training session in the use of life-saving appliances

Source: authors' own research.

As illustrated by Chart 6 , the vast majority of the respondents consider a training session covering the use of life-saving appliances that consists of a lecture accompanied by a demonstration, to be highly attractive. $62 \%$ of them deem this type of training good, whereas $17.5 \%$, perfect. Only $2.5 \%$ claim that such a training session is not attractive enough, $5 \%$ that it is mediocre, while for $12.5 \%$ of the respondents, it is satisfactory. 
The respondents also assessed the level of confidence in personal life-saving appliances on a scale from 1 to 5 , where 1 means low and 5 very high. The results are illustrated in Chart 7.

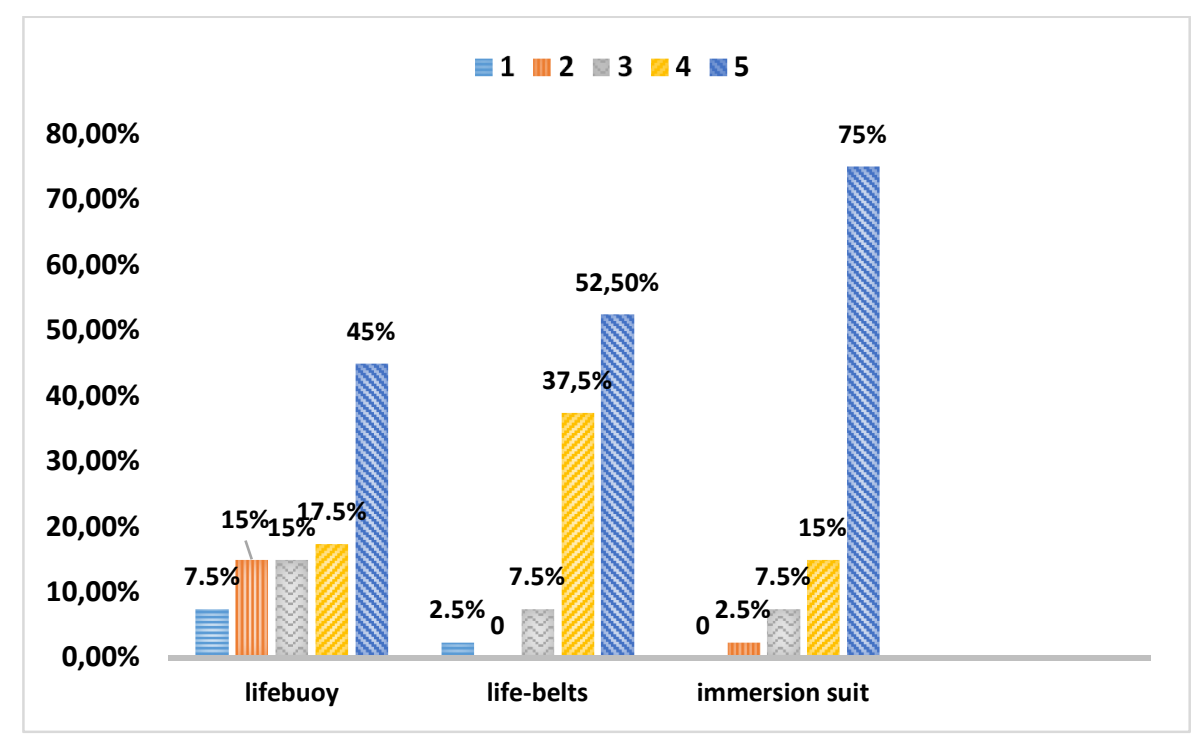

Chart 7. Level of trust in personal life-saving appliances

Source: authors' own research.

As Chart 7 shows, the respondents rated their level of confidence in personal life-saving appliances very highly. Immersion suits were met with $75 \%$ of the indications of very high confidence, life-belts with $52.5 \%$, and a lifebuoy with $45 \%$ respectively. With regard to low confidence, it appeared in a very small number of the respondents' indications. A lifebuoy is met with $7.5 \%$ of the indications of low confidence, while for belts these amount to $2.5 \%$ and the immersion suit was not met with any indications of being rated poorly. Average ratings at the level of 2, 3 or 4 were given only a few more indication. It is indicative of the fact that the sailors surveyed great confidence in personal life-saving appliances. Safety on the yacht is the most important factor to consider when sailing.

The sailors participating in the study were also asked to assess the level of trust and comfort in relation to buoyancy aids. They also rated them on a scale from 1 to 5 , where 1 means low and 5 means very high. This is illustrated in Chart 8.

Chart 8 also shows a very high level of trust and comfort towards buoyancy aids among the respondents. The respondents reported a very high level of trust (5) in both the waist and the harness, which received the highest marks from $35 \%$ and $50 \%$ of the sailors, respectively. With regard to the lowest marks in terms of the trust towards buoyancy aids, both the waist and the harness received 5\% of such indications. The chart shows a clear upward trend in the number of positive indications in the assessment of buoyancy aids. 


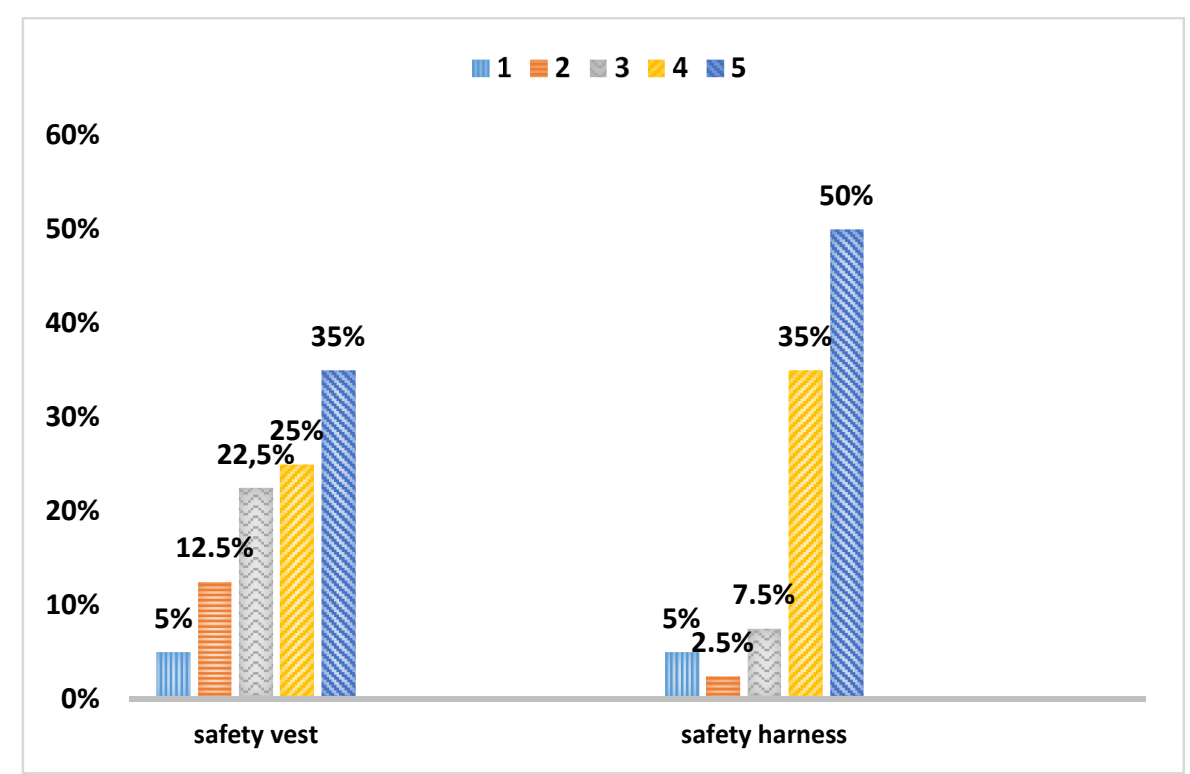

Chart 8. Level of trust and comfort towards buoyancy aids

Source: authors' own research.

\section{FINAL CONCLUSIONS}

The main motivation to enter the world of sailing seems to be the desire to spend time with interesting people while engaging in interesting activities. For some, this means good fun, while for others it is a sports competition and a path of self-improvement. Others seek contact with nature and a way to escape from the hustle and bustle of the city and other still want to simply stay close to the people they've been through a lot with and with whom they share their interests.

As the conducted research has shown, in Poland, this sport is more popular among men than women. The vast majority of sailors have received higher education. The majority of people who enjoy sailing live in cities ranging from 100,000 to 200,000 inhabitants. The largest number of sailors participating in the research comes from the following provinces: Pomorskie, Mazowieckie, Śląskie, Kujawsko-Pomorskie and Warmińsko-Mazurskie. The greatest number of sailing enthusiasts is between 40 and 50 years old. Most of the respondents rated their own skills as good. The vast majority of the sailors surveyed deem it necessary to have a set of life-saving appliances on board a yacht used for bay/coastal sailing. Over one-third of the respondents found themselves in a life-threatening situation while out at sea. While in a difficult situation, they made use of the available life-saving appliances. These were usually a life-belt, a life-jacket or an immersion suit. The surveyed sailors are aware of the necessity to use buoyancy aids while sailing. The vast majority of the respondents consider the attractiveness of a training session in the use of rescue equipment consisting of a lecture accompanied by a demonstration to be very high.

The respondents assessed their level of trust in personal life-saving appliances to be very high, they are also characterized by a very high level of trust and comfort towards buoyancy aids. 
More than others, the surveyed group shows signs of the aspirational nature of sailing this is an activity associated with prestige, one that allows to acquire good character traits, reveals what a person really is like. Sailors are perceived as courageous, responsible and determined. A weather forecast, a description of sailing routes and information on the attractions available on land are all important to them while on a voyage.

The decline of sailing ethics is a problem frequently indicated by the participants of the study. Fewer and fewer sailors know the rules and observe them in practice. The most frequently mentioned problems included those which contribute to the reduction of safety (e.g. the issue of overtaking, the behaviour in a channel, the consumption of alcohol on the deck) but also sailing aesthetics. Good practices are important in the sailing industry.

In an open question, which provided a chance to share their experiences, they surveyed sailors unequivocally claimed that a smart crew is not ashamed of using personal life-saving appliances. "Prevention is better than cure".

According to experts, sailing is a sport underestimated by the media, which leads to the persisting belief regarding its exclusiveness. The general public lacks knowledge about sailors and their achievements both present and historical.

\section{REFERENCES}

Dimensions of the Earth. Downloaded from: http://www.naukowiec.org/tablice/geografia/wymiary-ziemi_2734.html (Access: 2018.09.17).

https://www.onboardonline.com/industry-article-index/features/perspectives-on-the-safety-culture-in-yachting/ (Access: 2019.05.20).

Life-saving and security appliances. Downloaded from: https://www.zeglarstwo.waw.pl/ srodki.htm (Access: 2018.10.02).

LSA Code- characteristics of life-saving appliances. Downloaded from:

http://ratownictwo.am.szczecin.pl/index.php/dla-studentow/ratownictwo-morskie/31-kodekslsa (Access: 2018.09.17).

MARITIME SEARCH AND RESCUE SERVICE. Downloaded from: http://www.sar.gov.pl/pl/ (Access: 2019.02.01).

Monsarrat, N. (1988). The Cruel Sea [in Polish]. Warsaw: Wydawnictwo MON.

Radiopława EPIRB - basic information. Downloaded from: https://www.egmdss.com/gmdsscourses/mod/resource/view.php?id=485 (Acces: 2019.02 .29 ).

REGISTER OF SEA-GOING YACHTS 2017. Downloaded from: https://www.prs.pl/_files/parent519/rejestr_jac_2017.pdf (Acces: 2019.01.29).

Sailing forums. Downloaded from: https://forum.zegluj.net/, https://www.sailforum.pl/ (Acces: 2019.01.29).

SEA Light. Downloaded from: http://sealight.pl/ (Acces: 2019.05.29).

Sommer, H., Sommer, H., Zakrzewski, G. (2018). Attitudes of contemporary academic youth in an emergency situation (with the use of rescue equipment). Humanities and Social Sciences HSS, Vol. XXIII, 25 (2) (Acces: 2019.01.29).

The $9^{\text {th }}$ International Regatta Eljacht Cup 2018. Downloaded from: http://www.eljachtcup.pl/ (Acces: 2018.10.02).

https://puc.overheid.nl/nsi/doc/PUC_2393_14/5/(Acces: 2019.01.29). 


\section{LEGAL ACTS}

Regulation of the Minister of Sport and Recreation of 9 April 2013 on practising water tourism. Journal of Laws from 2013, item 460. Downloaded from: http://prawo.sejm.gov.pl/isap.nsf/ download.xsp/WDU20130000460/O/D20130460.pdf (Access: 2018.10.02).

DOI: 10.7862/rz.2019.hss.20

The text was submitted to the editorial office: March 2019.

The text was accepted for publication: June 2019. 